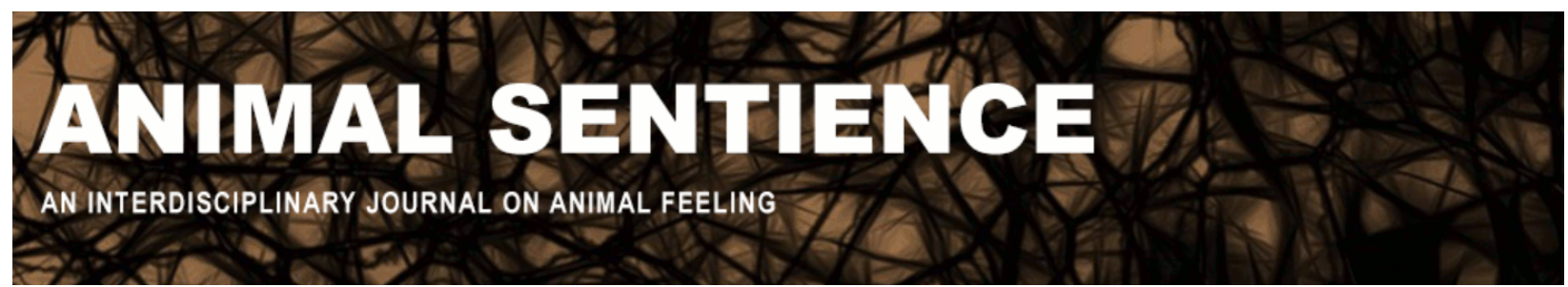

$\mathrm{Ng}$, Yew-Kwang (2016) Consciousness and evolutionary biology. Animal Sentience 11(11)

DOI: $10.51291 / 2377-7478.1179$

Date of submission: 2016-11-21

Date of acceptance: 2016-11-23

(c)

This article has appeared in the journal Animal

Sentience, a peer-reviewed journal on animal

cognition and feeling. It has been made open access,

free for all, by WellBeing International and deposited

in the WBI Studies Repository. For more information,

please contact

wbisr-info@wellbeingintl.org.

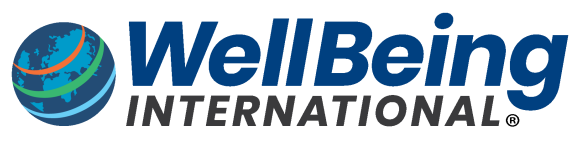

SOLUTIONS FOR PEOPLE, ANIMALS AND ENVIRONMENT 


\title{
Consciousness and evolutionary biology
}

Commentary on Reber on Origins of Mind

\section{Yew-Kwang $\mathrm{Ng}$ \\ Division of Economics, Nanyang Technological University}

\begin{abstract}
Reber's axiom: "Any organism with flexible cell walls, a sensitivity to its surrounds and the capacity for locomotion will possess the biological foundations of mind and consciousness" does not seem to be supported by things we know and the logic of evolutionary biology. The latter leads to the conclusion that conscious species are flexible in their behavior (rather than in their cell walls), as argued in $\mathrm{Ng}(1995,2016)$. Locomotion may be completely hard-wired and need not involve consciousness. It is hard enough to explain how consciousness could emerge in a sophisticated brain: Isn't it a harder problem to show or see how consciousness could emerge in a much more primitive organism, as Reber suggests? As we are unlikely to solve the hard problem of consciousness any time soon, surely a more immediate problem is to ascertain with high probability which species are capable of welfare (enjoyment and suffering).
\end{abstract}

Keywords: consciousness, mind, evolutionary biology, flexible behavior, animal welfare

Yew-Kwang Ng, Winsemius professor in economics, Nanyang Technological University, is a fellow of the Academy of Social Sciences in Australia and Distinguished Fellow of the Economic Society of Australia. His recent books include: Common Mistakes in Economics by the Public, Students, Economists and Nobel Laureates (open access); and Markets and Morals, Cambridge University Press (forthcoming). http://www.ntu.edu.sg/home/ykng/

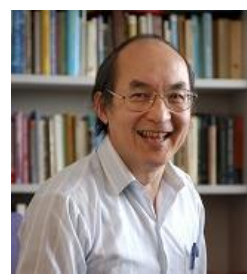

The main point of Reber's (2016) important argument is the following:

"Axiom: Mind and consciousness are not unique features of human brains. They are grounded in inherent features present in simpler forms in virtually every species. Any organism with flexible cell walls, a sensitivity to its surrounds and the capacity for locomotion will possess the biological foundations of mind and consciousness" (p.4).

The first sentence on non-uniqueness is obviously non-controversial. The jump to all species with flexible cell walls and locomotion capacity, however, is highly debatable, as argued below. Here, just a quick note that the requirement of "a sensitivity to its surrounds" may make the axiom or statement a tautology if "sensitivity" requires subjectivity. My understanding of true subjectivity entails consciousness. On the other hand, if subjectivity is not required for "sensitivity," then its sufficiency, even with other parts (flexible cell walls and locomotion), for consciousness seems doubtful.

Reber (2016, pp. 2-3; all unnamed page references are to this same source) calls his theory of consciousness "bio-centric," embedded in evolutionary biology, and notes it "will 
stand (or fall) on evolutionary biological principles." However, he does not seem to have utilized evolutionary biology sufficiently to help answer the hard problem of consciousness. As I have

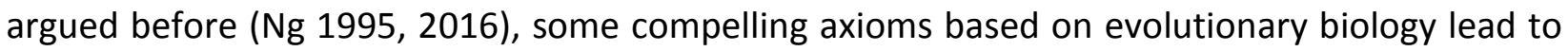
the conclusion that conscious species are flexible in their behavior, instead of being completely pre-programmed by genetics (hard-wired). This allows us to exclude behaviorably non-flexible species from those with consciousness. Though it is still difficult to establish which species are flexible in behaviour, it is at least more tractable. Reber's "flexible cell walls, a sensitivity to its surrounds and the capacity for locomotion" are related to flexibility in behavior, but not fully. For example, locomotion may be completely hard-wired. Movement towards sources of light may surely be hard-wired, with no need for flexible, conscious decisions on the spot. Thus, "sensitivity to light" may also be purely an objective chemical reaction with no subjectivity involved. Similarly, as commentator Michael Woodruff (2016, p. 2) shows, we can explain "bacterial chemotaxis without the introduction of sentience." On the other hand, subjectively sensing some aspects of the objective world already entails sentience, with the problem of tautology, as mentioned above.

The claim "that all organisms have shared internal experiences and feelings, that all animals share a broad spectrum of sentience" (p. 2; italics added) is thus likely excessive. The following claim is similar: "When we encounter a wounded creature, even one with whom our common ancestry is in the distant past, we feel an empathic connection - and that affective reaction is a hint that we apprehend the shared emotive valence, the common sensory core. That starfish curling its arms when cut experiences pain and it is on a continuum with my pain when my arm is cut" (pp. 3-4). Empathy on one side does not establish sentience on the other. Though our previous inclination towards condemnation of mistaken anthropomorphism was excessive, such a mistake is certainly possible.

As quoted by Reber, Harnad (2016) asks

"... if organisms do have minds, the hard problem is to explain how and why such survival/reproduction machines would evolve minds: What is the added causal role and adaptive value of having a mind, over and above the causal role and adaptive value of just having the behavioral capacities themselves?" (Emphasis in original.)

Reber questions the usefulness of focusing on the "added" elements. However, this correct focus led to the conclusion that conscious species are flexible as mentioned above.

One of Reber's main points is that instead of trying to see or show how mind or consciousness emerge in a brain of sufficient sophistication it is better go beyond brains to the level of more primitive organisms: all those with flexible cell walls, sensibility to their surrounds, and capacity for locomotion. We would still need a miracle to explain how such organisms could have the more primitive subjectivity but, in Reber's view, this would be a much smaller miracle. I see all kinds of (true) subjectivity as conscious or mental, though with different degrees of complexity and sophistication. The very first step from no subjectivity to its presence, no matter how primitive, does indeed seem like a miracle unless a causal explanation can be found. Commentator Ristau (2016) is certainly right that no one knows the explanation. Commentators Ball (2016) and Woodruff (2016) do seem to be asking too much of Reber in expecting him to 
solve this hard problem. However, I do not see how the miracle is made much smaller by going back to primitive organisms. It is hard enough (such that no one has an answer) a problem to explain how consciousness could emerge in a sophisticated brain; isn't it a harder problem to explain how it could emerge in a much more primitive organism? What we have to see or show is only slightly smaller (the basic subjectivity, conscious, or mental aspect is essentially the same), but we have fewer ingredients available to start with. Consider the following analogy. It is ingenious or takes the cooperation of many talents to be able to build a computer that could beat the top human chess players using only (say) 10,000 individual items of equipment. Isn't it even more difficult, if not impossible, to build one using only 100 pieces, even if just for the purpose of beating an average chess player?

Perhaps this partly explains why Reber relies on an intrinsic property: "Particular kinds of physical matter carry with them particular properties. Particular kinds of biological stuff carry with them particular properties. In one case the properties are forces; in the other they are subjective experiences" (p. 7). I prefer to go with Ristau in requiring further explanations in both physics and sentience. "Simply stating that sentience is a property of certain kinds of cells is ... not an answer." Moreover, Reber's theory does not seem to be supported by many things we know for sure: We lose consciousness when our brains are sleeping without dreaming; we lose certain mental abilities when certain parts of our brains are damaged (Ramachandran 2011); we do not lose consciousness when our arms or legs are lost; when the two brain hemispheres are separated, we have two minds (Gazzaniga 1970); etc.

The hard problem of consciousness (also dubbed the "world knot" by Schopenhauer $1906 / 2014$ ) is unlikely to be resolved any time soon. Especially for the authors and readers of Animal Sentience, a more immediately important problem is to know with high and increasing degrees of probability which species of animals are capable of affective sentience. For nonsentient species, we do not have to care about their welfare, as they do not have any welfare. They may still be of value, but only instrumental value in contributing to the welfare of the affectively sentient species, including in maintaining a livable environment for a long time. Here again, the conclusion that conscious species are flexible in their behavior is of importance in helping us to classify which species or which phyla or classes of species are likely to be capable of enjoyment and suffering and which are not. Answering this question as best we can is one of the important problems on which Animal Sentience should focus. 


\section{References}

Ball, D. (2016). No help on the hard problem. Animal Sentience 2016.149.

Gazzaniga, M. S. (1970). The Bisected Brain. Appleton-Century-Crofts, New York.

Harnad, S. (2016). Animal sentience: The other-minds problem. Animal Sentience 2016.001.

$\mathrm{Ng}, \mathrm{Y}-\mathrm{K}$. (1995). Towards welfare biology: Evolutionary economics of animal consciousness and suffering, Biology and Philosophy, 10, 255-285.

$\mathrm{Ng}$, Y-K. (2016). How welfare biology and commonsense may help to reduce animal suffering. Animal Sentience 2016.007.

Ramachandran, V. S. (2011/2012). The Tell-Tale Brain. Windmill Books, London.

Reber, A. S. (2016). Caterpillars, consciousness and the origins of mind. Animal Sentience 2016.106.

Ristau, C. A. (2016). Beginnings: Physics, sentience and LUCA. Animal Sentience 2016.134.

Schopenhauer, A. (2014). The World as Will and Idea. Dobimick Publishing.

Woodruff, M. L. (2016). Bacteria and the cellular basis of consciousness. Animal Sentience 2016.126. 